\title{
Retraction Note to: Chitosan prevents oxidative stress-induced amyloid $\beta$ formation and cytotoxicity in NT2 neurons: involvement of transcription factors Nrf2 and NF-KB
}

\author{
Fariba Khodagholi ${ }^{1}$ - Bahareh Eftekharzadeh ${ }^{1} \cdot$ Nader Maghsoudi $^{1} \cdot$ Parisa Fathi Rezaei ${ }^{1}$
}

Published online: 5 February 2022

(c) Springer Science+Business Media, LLC, part of Springer Nature 2022

\section{Retraction to: Molecular and Cellular Biochemistry (2010) 337:39-51 \\ https://doi.org/10.1007/s11010-009-0284-1}

The Editors in Chief have retracted this article because of significant concerns regarding the western blots presented in Figs. 2A, 4A, 5A, 7A and 8A, which question the integrity of the data. Furthermore, there is a substantial overlap of text with the following articles [1,2]. This has led to a loss of confidence in the presented results and the conclusions drawn in this study. All authors agree to this retraction.

\section{References}

1. Eftekharzadeh B, Khodagholi F, Abdi A, Maghsoudi N (2010) Alginate protects NT2 neurons against $\mathrm{H} 2 \mathrm{O} 2$-induced neurotoxicity. Carbohyd Polym 79(4):1063-1072

2. Eftekharzadeh B, Maghsoudi N, Khodagholi F (2010) Stabilization of transcription factor Nrf2 by tBHQ prevents oxidative stress-induced amyloid $\beta$ formation in NT2N neurons. Biochimie 92(3):245-253

Publisher's Note Springer Nature remains neutral with regard to jurisdictional claims in published maps and institutional affiliations.

The original article can be found online at https://doi.org/10.1007/ s11010-009-0284-1.

Fariba Khodagholi

khodagholi@sbmu.ac.ir

1 Neuroscience Research Center, Shahid Beheshti University of Medical Science, Tehran, Iran 